ISSN: 1641-4713; e-ISSN: 2081-1160

DOI: https://doi.org/10.36551/2081-1160.2021.27.113-132

\title{
A constituição do "eu" em entrevistas com descendentes de italianos no Brasil: Tempo e espaço como marcas de memória e identidade
}

\author{
The constitution of the "I" in interviews with Italian descendants \\ in Brazil: Time and space as memory and identity traces
}

\author{
Elisabetta Santoro \\ Universidade de São Paulo (USP), Brasil \\ ORCID iD: https://orcid.org/0000-0001-7577-368X \\ E-mail: esantoro@usp.br \\ Giliola Maggio \\ Universidade de São Paulo (USP), Brasil \\ ORCID iD: https://orcid.org/0000-0003-1288-6681 \\ E-mail: gilimaggio@usp.br
}

Recepción: 24.12.2020

Aprobación: 25.06.2021

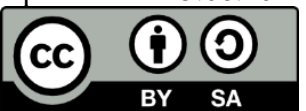

Resumo: Na sociedade brasileira contemporânea, a presença italiana ligada às várias épocas da migração é ainda hoje muito forte. Partindo do pressuposto que narrativas de descendentes de italianos podem ser um canal de acesso privilegiado a essa presença, o objetivo deste artigo é analisar o que dizem sobre a Itália e ser "italianos" aqueles que são italianos de origem, mas brasileiros de nascimento e que tipo de representações vinculam à memória de seu passado familiar. $\mathrm{O}$ corpus aqui analisado é composto por cinco entrevistas com uma duração entre 20 e 50 minutos cada uma. Trata-se de uma amostra que permite iniciar reflexões e reconhecer recorrências e foi selecionada a partir do material coletado no âmbito de um projeto maior, que reúne relatos, narrativas e testemunhos a respeito de vários aspectos de histórias de vida de descendentes de italianos no Brasil. As entrevistas foram gravadas seguindo a abordagem metodológica da História Oral e a análise, de tipo qualitativo e exploratório, utiliza como referência as teorias da enunciação e se concentra, em especial, na observação de como se constitui o "eu" em sua relação com as categorias do tempo e do espaço.

Palavras-chave: descendentes de italianos, imigração no Brasil, discurso, memória, identidade, história oral. 


\begin{abstract}
In contemporary Brazilian society, the Italian presence linked to the various periods of migration is still very strong today. Assuming that narratives of Italian descendants can be a privileged access to this presence, the aim of this article is to analyze what those who are Italian by origin and Brazilian by birth say about Italy and about being "Italians", and which type of representations they associate with the memory of their families' past. The corpus analyzed here consists of five interviews lasting from 20 to 50 minutes each. It is a sample that allows us to make reflections and recognize recurrences and it was selected from the material of a larger project, which brings together reports, narratives and testimonies about various aspects of the life histories of Italian descendants in Brazil. The interviews were recorded following the methodological approach of Oral History and the qualitative and exploratory analysis, based on the theories of enunciation, focuses, in particular, on how the "I" is constituted in its relationship with the categories of time and space.
\end{abstract}

Keywords: descendants of Italians, immigration in Brazil, discourse, memory, identity, oral history.

\title{
1. INTRODUÇÃO ${ }^{1}$
}

Entrevistas com descendentes de italianos, residentes no Brasil, que estão sendo coletadas no âmbito do grupo de pesquisa "Língua, Identidade e Memória: o italiano dos italianos do Brasil" (GLIM) e do LEER (Laboratório de Estudos sobre Etnicidade, Racismo e Discriminação), junto à Universidade de São Paulo, contêm os relatos sobre os quais iremos nos debruçar neste artigo. Gravadas em áudio e vídeo e utilizando como metodologia, para a definição de suas características, as indicações da História Oral (Ferreira, 1998; Matos \& DeSenna, 2011; Meihy \& Holanda, 2007; Weber, 2013), essas entrevistas motivaram as pessoas que participaram a narrar sua relação com a Itália e a "italianidade" a partir das memórias de cada um e das histórias individuais e familiares.

Além de representar uma contribuição para pensar a história da migração italiana no Brasil, a partir da perspectiva de seus descendentes, essas narrativas autobiográficas nos permitem acessar o mundo de "pessoas comuns", que se confrontam com suas lembranças a partir do "agora" do momento da enunciação. A análise de alguns traços presentes nas entrevistas pode mostrar como se constroem nos discursos dos descendentes as "histórias" e as "memórias" ligadas à sua ascendência italiana, partindo do pressuposto, como escreveu Halbwachs, que "cada memória individual é um ponto de vista sobre a memória coletiva, que este ponto de vista muda conforme o lugar que ali eu ocupo, e que este lugar mesmo muda segundo as relações que mantenho com outros meios." (Halbwachs, 1999, p. 50) A análise que apresentamos se concentra, portanto, essencialmente no "como" se constrói a narrativa e tem por objetivo trazer à tona características de algumas "memórias individuais", que podem nos dar indícios para refletir sobre a "memória coletiva".

\footnotetext{
${ }^{1}$ Os dados do trabalho aqui apresentado resultam de um projeto, realizado em estreita colaboração entre as duas autoras. Quanto à efetiva redação deste artigo, Elisabetta Santoro é responsável pelos parágrafos 1, 2, 4, 5, 6 e 7, e Giliola Maggio, pelo parágrafo 3.
} 
Não é nosso objetivo aqui - e nem seria possível - definir o que "é" a identidade italiana no contexto específico ao qual procuramos ter acesso por meio dos entrevistados. Ao contrário, o presente estudo visa a analisar o que se depreende das narrativas de descendentes de italianos no Brasil sobre elementos que eles próprios atribuem à "italianidade" e, sobretudo, de que forma esses traços vêm à tona por meio da seleção operada pela memória.

Tendo esses conceitos como fio condutor, o artigo está dividido em duas partes: na primeira parte, serão apresentados, para contextualizar as entrevistas, alguns aspectos essenciais da imigração italiana no Brasil e será ilustrado o projeto de pesquisa, seus principais objetivos e o roteiro de perguntas utilizado; na segunda parte, com base na seleção de trechos de cinco entrevistas, que são aqui apenas uma amostra de um corpus mais amplo, buscaremos mostrar como se constroem elementos essenciais das narrativas, sobretudo, em relação à constituição do "eu", tendo como referência as teorias da enunciação (entre outros, Benveniste, 1995; Fiorin, 1995).

\section{AlgunS NÚMEROS DA MIGRAÇÃO ITALIANA NO BRASIL}

A migração italiana mais significativa do ponto de vista numérico, também conhecida como a "grande emigração", iniciou no Brasil na segunda metade do século XIX, trazendo para o Brasil quase um milhão de italianos: "868.178, segundo as estatísticas oficiais do reino e 949.588, segundo aquelas do país 'importador"' (Franzina, 1995, p. 452). O fenômeno é muito complexo, mas podemos considerar que o crescimento demográfico na Itália e, ao mesmo tempo, a necessidade de suprir a mão-de-obra no Brasil, estão entre os principais fatores responsáveis pela primeira grande leva imigratória, entre os anos 1887 e 1902 . A periodização relativa à chegada de italianos no Brasil nos anos posteriores é apresentada nos estudos de diferentes maneiras, dependendo dos objetivos e das perspectivas adotadas. De qualquer forma, sabe-se que continuou intensa até, pelo menos, 1914, quando do início da Primeira Guerra, e prosseguiu nos anos seguintes, embora com números menos expressivos. Apenas para termos mais algumas referências, quem considera até o ano de 1930, afirma que teria sido atingido cerca um milhão e 300 mil italianos (SVIMEZ, 1954, p. 123-124); outras estatísticas, que trazem dados até 1953, indicam que o Brasil teria recebido cerca de um milhão e 500 mil migrantes.

Mas o que dizem hoje sobre sua relação com a Itália os descendentes desses italianos, que já nasceram no Brasil? De que maneira falam da relação com essa parte de sua história e se constituem como sujeitos? Que tipo de representações vinculam à memória de seu passado familiar? 
Considerando que se calcula que haja atualmente no Brasil pelo menos vinte milhões de descendentes de italianos ${ }^{2}$, essas perguntas não parecem irrelevantes, até mesmo porque, ao procurar respondê-las, podemos tentar compreender melhor tanto o passado quanto o presente de fenômenos migratórios que alteram o curso da história e transformam os processos identitários e as relações entre diversas culturas.

\section{UM PROJETO PARA “DAR VOZ” À MEMÓRIA}

A ideia que, para procurar entender melhor as complexas questões mencionadas até aqui, fosse necessário dar voz aos diretos interessados, nasceu em 2013 - e continua até hoje - com o objetivo de ouvir os protagonistas desse fragmento de história, para entender de que forma falam hoje de como vive(ra)m a relação com sua ascendência italiana.

Nasceu assim o mencionado grupo de pesquisa, que se colocou como principal objetivo coletar histórias e memórias de descendentes de migrantes italianos, em particular daqueles que fixaram residência no Estado de São Paulo, região que acolheu um elevado percentual dos que chegaram. A migração italiana no Brasil já foi tema de muitas pesquisas com diferentes enfoques, que se concentraram tanto sobre o fenômeno como um todo, quanto sobre regiões ou aspectos particulares e trouxeram contribuições essenciais para a compreensão de sua complexidade $^{3}$. A especificidade da proposta que apresentamos aqui consiste na perspectiva de análise, cujo objetivo não é tanto observar "o que" os entrevistados dizem, mas "como" dizem o que dizem e como deixam transparecer em seus discursos características de sua própria relação com a Itália e com essa parte de sua identidade.

De fato, a hipótese inicial que levou à constituição do projeto é que registrar o relato dos descendentes de italianos por meio de entrevistas permitiria, ao longo do tempo, não só uma espécie de "mapeamento" das histórias de vida ligadas à imigração italiana no Brasil, mas nos daria também a possibilidade de analisar o discurso dos "filhos da imigração" e a maneira como se constrói, mesmo porque a entrevista, como narração oral ligada ao ego-hic-nunc do momento da enunciação, facilitaria a observação com o olhar do "agora" dos fatos do passado e da experiência vivida.

\footnotetext{
${ }^{2}$ Não temos dados mais precisos, visto que o censo brasileiro não prevê perguntas sobre a(s) nacionalidade(s) de origem dos cidadãos brasileiros. Embora não especifique a fonte, o site da Embaixada Italiana no Brasil (http://www.ambbrasilia.esteri.it/) traz alguns números e, em 2013, foi divulgado que os cidadãos brasileiros de origem italiana chegariam a extraordinários 30 milhões.

${ }^{3}$ Dar conta do imenso número de pesquisas realizadas nessa área é tarefa impossível. Por essa razão, citamos aqui apenas alguns dos estudos, que são referências obrigatórias para quem se aproxima desse tema: Cenni, 2011; Franzina, 1995, 2006 [1976]; Klein, 1989; Trento, 1989; Truzzi, 2016.
} 
De acordo com Fiorin (1995),

Como a pessoa enuncia num dado espaço e num determinado tempo, todo espaço e todo tempo organizam-se em torno do "sujeito", tomado como ponto de referência. Assim, espaço e tempo estão na dependência do eu, que neles se enuncia. $\mathrm{O}$ aqui é o espaço do eu e o presente é o tempo em que coincidem o momento do evento descrito e o ato de enunciação que o descreve. A partir desses dois elementos, organizam-se todas as relações espaciais e temporais. Porque a enunciação é o lugar de instauração do sujeito e este é o ponto de referência das relações espaço-temporais, ela é o lugar do ego, hic et nunc. (p. 26)

As entrevistas, gravadas em laboratório, são faladas em português brasileiro e semidirigidas, visto que partem de uma série fixa de perguntas, sem que isso signifique, contudo, impor limites de tempo para as respostas ou fornecer instruções. O roteiro para as perguntas permite obter dos entrevistados dados comparáveis e facilita a busca de eventuais recorrências ou traços distintivos que podem contribuir tanto para identificar similaridades, quanto para evidenciar diferenças.

Para estabelecer quais seriam as perguntas, seguimos, como já foi dito, as indicações da História Oral, definida por Meihy \& Holanda (2007)

como um conjunto de procedimentos que se inicia com a elaboração de um projeto, desdobra-se em entrevistas ou considerações da oralidade que demandam cuidados com o estabelecimento de textos/documentos que podem ser analisados, arquivados para uso público, mas que tenham um sentido social. (p. 15)

Apoiando-nos, em especial, no terceiro ramo da História Oral, que busca as tradições orais com base em observações, tradições e entrevistas, tentamos conciliar o tempo presente e as memórias desses descendentes de imigrantes. De fato, a História Oral define a metodologia de coleta e análise de dados, partindo da memória individual e das experiências vividas para refletir sobre a história recente com base nos testemunhos de quem a viveu. Assim, parte-se da memória individual para poder traçar o perfil de um grupo, busca-se preservar a memória física e espacial e ter acesso ao que um grupo de indivíduos viveu, para procurar saber de que forma foram percebidas determinadas experiências, a fím de sistematizar as lembranças individuais inseridas no coletivo.

De acordo com Meihy (2012),

[...] Reafirmando que sem democracia não há história oral, parte-se do suposto de que a organização da leitura do passado pela memória coletiva se reordena a partir de eventos gravados no imaginário e expressos na vida cotidiana. Nesse sentido, lê-se por imaginário, o conjunto de representações assumidas e manifestadas de diferentes maneiras. (p. 411)

São esses "eventos gravados no imaginário" que as perguntas feitas aos participantes visavam a trazer para o discurso: falar sobre a memória, transformar em palavras os fatos lembrados, recriar sequências, comentar a partir do ponto de vista do $e u$, do aqui e do agora poderia dar forma às representações e mostrar de que forma esse passado se constrói. Além disso, pensar na “[...] memória como 
presença do passado, como uma construção psíquica e intelectual de fragmentos representativos desse mesmo passado, nunca em sua totalidade, mas parciais em decorrência dos estímulos para a sua seleção" (Matos \& DeSenna, 2011, p. 96), pode significar escolher maneiras adequadas de tentar alcançar os objetivos que uma pesquisa se propõe.

Tendo tudo isso em vista, ficou estabelecido que as perguntas para as entrevistas seriam as seguintes:

1. O que você sabe de como a sua família veio para o Brasil?

2. Vieram diretamente para São Paulo ou ficaram em outras cidades antes?

3. Você se lembra de alguma história sobre a Itália que se conta(va) na sua casa?

4. E que língua se fala(va) na sua casa? Alguém ainda fala italiano? Você já ouviu alguém falando italiano?

5. E como você acha que foi ser um italiano em São Paulo? O que você acha que se pensa dos italianos no Brasil e, em especial, em São Paulo?

6. Você se lembra se na sua casa alguém lia jornais em italiano?

As duas primeiras perguntas têm o objetivo de ouvir como os entrevistados falam de sua família de origem e o que sabem sobre como e onde começou a parte brasileira de sua história. Ocorre com bastante frequência no Brasil que se encontrem pessoas que não sabem exatamente qual a proveniência de seus antepassados italianos ou o que eles fizeram no início de sua estada no país. As perguntas são, portanto, relevantes tanto se houver uma resposta, quanto se não houver. Se os entrevistados têm informações sobre a região de origem de seus antepassados e sobre como foi sua chegada ao Brasil, podemos, inclusive, ir construindo um mapeamento que pode confirmar o que já se sabe ou acrescentar dados novos. Caso os entrevistados não tenham essas informações, a constatação também é relevante para a finalidade da pesquisa, pois nos ajuda a confirmar uma ausência significativa.

As perguntas (3) e (4) foram formuladas pensando que fariam aflorar histórias de família e aspectos da vida linguística dos entrevistados, imaginando que sejam duas questões particularmente significativas na construção da ideia de "italianidade", que pode ser representada por um pertencimento real ou reconstruído pela memória. De fato, faz parte dos interesses do grupo de pesquisa, saber o que contam os descendentes sobre o que acontecia em suas famílias e o que selecionam, entre suas lembranças cotidianas, para falar sobre se havia alguma presença da língua italiana, em geral, como se sabe, quase completamente excluída da vida da maioria dos descendentes. 
As razões pelas quais isso se deu são inúmeras e vão desde as peculiaridades da constituição da língua italiana a partir da época pós-unitária até suas relações, no caso dos migrantes, com o português brasileiro, temas focalizados em inúmeros estudos (Balthazar, 2016; Frosi \& Mioranza, 1975; Honório, 2016; Manfroi, 1975). Embora não seja objetivo deste artigo dar conta de toda essa complexidade, algumas considerações podem contribuir para termos um panorama dos principais aspectos que influenciaram a situação linguística dos migrantes.

Em primeiro lugar, cabe relembrar que eles chegaram em massa como mão de obra para as fazendas a partir do final do século XIX, sendo tratados como "colonos ignorantes", cuja língua e cultura não podiam competir com a língua e a cultura consideradas hegemônicas dos "donos da terra".

Em segundo lugar, é importante lembrar que, muitas vezes, a "língua dos italianos", pelo menos até as primeiras décadas do século XX, era essencialmente o dialeto de sua região. De fato, só após sua tardia unificação, em 1861, colocouse na Itália a questão da língua nacional. Nas leituras mais pessimistas dos dados, como a de De Mauro (1963), apenas 2,5\% da população poderia ser considerada italófona. Em outras interpretações, como a de Castellani (2009), o percentual aumenta a cerca de um décimo dos habitantes da Itália daquela época, mas uma verdadeira mudança na observação do fenômeno foi dada por Bruni (2013), que defendeu uma visão mais ampla, que abdicasse da rígida separação entre o italiano dos poucos escolarizados e o dialeto dos muitos analfabetos, incluindo também os "italófonos imperfeitos" em sua contagem. Aumentam os números nessa visão, mas, mesmo assim, não se desfaz uma constatação reportada por Cenni (2011): chegando ao Brasil, os italianos seriam, de qualquer forma, obrigados a "aprender" uma língua e optavam pelo português, por ser a língua que poderiam usar também fora da comunidade dos italianos.

Outro fator determinante que agiu com a mesma, ou maior força, sobre esses grupos (de Oliveira, 2008), foi, na Era Vargas (1937-1945), a proibição explícita das línguas estrangeiras, bem exemplificada pelo quadro reproduzido a seguir (Fig. 1).

Nesse período, a escola funcionou como vetor de uma ideologia baseada na política da "brasilidade", impondo a todas as instituições brasileiras o ensino em língua portuguesa como forma de valorização da "nacionalidade". Desse modo, "se pensarmos no caso da escola, [...] veremos como ela consegue despovoar a língua. Purificando-a. Descarnando-a. Não deixando mais nada do que os seus ossos" (Scherer, 2007, p. 352). 
FIGURA 1 - A PROIBIÇÃO DE FALAR LÍNGUAS ESTRANGEIRAS EM PÚBLICO

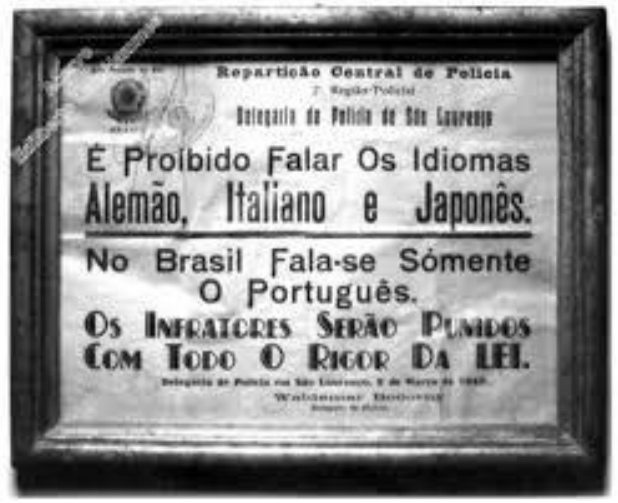

Fonte: Foto do acervo de Edilberto Luiz Hammes, publicada em "Folha Pomerana" No 231, 2018 (17 de março de 2018). ${ }^{4}$

Hall (2003) descreve o fenômeno, afirmando que

a formação de uma cultura nacional contribuiu para criar padrões de alfabetização universais, generalizou uma única língua vernacular como o meio dominante de comunicação em toda a nação, criou uma cultura homogênea e manteve instituições culturais nacionais, como, por exemplo, um sistema educacional nacional. (p. 49)

Os efeitos desse silenciamento reverberam ainda hoje, nas entrelinhas dos discursos dos italianos e de seus descendentes, além de serem percebidos no cotidiano da sociedade brasileira, na qual a presença da imigração italiana parece estar em todo lugar e em lugar nenhum, já que há quase sempre "algo de italiano" nas pessoas, nos lugares, nas coisas, mas há também contornos indefinidos que permeiam o reconhecimento dessa ligação. ${ }^{5}$

Com a pergunta (5), a relação com o tema da identidade é mais direta. Nosso interesse é entender de que maneira os "protagonistas" dessa história descrevem os italianos para poder refletir sobre imagens, representações e estereótipos. Segundo Amossy (2011),

[...] As representações coletivas fixas, necessariamente sumárias, que se atribuem a cada categoria, têm [...] um impacto considerável na identidade social. Além disso, elas afetam as relações que os grupos e seus membros mantêm entre si. A preocupação de detectar

\footnotetext{
${ }^{4} \mathrm{O}$ quadro aqui reproduzido era obrigatoriamente exposto em casas comerciais, repartições públicas, clubes, ou em locais de aglomeração pública. Esse foi produzido pela Delegacia de São Lourenço do Sul, RS, em 2 de março de 1942, atendendo à legislação da Ditadura Vargas quanto à proibição de se falar línguas estrangeiras em público, em especial dos países do Eixo, da Segunda Guerra Mundial: Alemanha, Japão e Itália.

${ }^{5}$ Para um aprofundamento da questão do silenciamento da língua materna e de sua relação com a memória, baseada no estudo da migração italiana no Brasil, veja-se Payer (2006).
} 
imagens e crenças estigmatizadas por um grupo e seus membros explica o interesse mostrado desde o início do século sobre estereótipos étnicos e raciais. (p. 34, grifo da autora) ${ }^{6}$

No entanto, argumenta Amossy (2011), quando não levam ao preconceito e à discriminação, os estereótipos têm um papel positivo para a construção da identidade social, pois constituem representações e, portanto, pontos de partida que, no confronto com o outro, podem ou não ser reformulados.

Por fim, a pergunta (6) também visa a comparar os dados oficiais com a voz de "quem viu e viveu". Nesse caso específico, o tema são os jornais em língua italiana, que constituem um fenômeno à parte e merecem um breve esclarecimento. Em seu estudo sobre a migração italiana no Brasil, ao falar da imprensa em língua italiana e de seu considerável número, Trento enfatiza como isso representa uma surpresa, pois esse dado faria presumir um público que, na realidade, pareceria não ter existido (Trento, 1989, p. 184). De fato, as pesquisas mostram que nas primeiras décadas do século XX o jornal de maior tiragem, depois do diário Estado de São Paulo, era um jornal italiano chamado Il Fanfulla, fundado em 1893, transformado pouco depois em jornal diário e assim publicado até 1965 (Trento, 1989, p. 491), quando passou a ser semanário. ${ }^{7}$ Na realidade, se o público dos jornais em italiano tivesse sido formado somente por agricultores, todos ou quase todos analfabetos ou semianalfabetos, ou por pequenos vendedores ambulantes que, de acordo com os dados, representavam a parte mais consistente da colônia italiana (Hutter, 1986), pareceria impossível explicar o forte fenômeno do jornalismo italiano no Brasil e, em particular, em São Paulo. Há, no entanto, opiniões diversas com relação ao grau de escolarização entre os migrantes italianos e algumas das fontes aludiriam à existência de possíveis leitores (Vezzelli, 2015). As respostas que estamos coletando poderão constituir um elemento de comparação e poderão não apenas fornecer dados sobre mais esse

\footnotetext{
${ }^{6}$ No original: [...] les représentations collectives figées, nécessairement sommaires, qui s'attachent à chaque categorie ont donc un impact considérable sur l'identité sociale. Qui plus est, elles influent sur les relations que les groupes et leurs membres individuels entretiennent entre eux. Le souci de détecter les images et les croyances que stigmatisent un groupe et ses membres individuels explique l'intérêt porté dès le début du siècle aux stéréotypes ethniques et racieux.

${ }^{7}$ Mais algumas observações sobre o Fanfulla. Em 1941, foi editado em português, para atender às determinações legais sobre as línguas estrangeiras no Brasil e durante a Segunda Guerra Mundial, deixou de circular, voltando a ser publicado diariamente, em italiano, em 1947. Em 1966, foi publicado mais uma vez como semanário, com o nome La Settimana, para, em 1979, passar a chamarse La Settimana del Fanfulla. Houve outra tentativa recente de retomada, inclusive do nome em 2001 e, em 2011, tornou-se quinzenal. A partir de 2014, transformou-se em uma publicação unicamente digital, apresentando-se como "O jornal dos italianos no Brasil desde 1893". Em 2020, o Centro de Documentação e Memória da Unesp, por meio de uma parceria firmada com o CAPH (Centro de Apoio à Pesquisa "Sérgio Buarque de Hollanda"), da Faculdade de Filosofia, Letras e Ciências Humanas da USP, concluiu uma parte da digitalização do jornal, para disponibilização on-line.
} 
aspecto da história italiana em São Paulo, mas mostrar se e como a leitura dos jornais possuía um espaço nas casas dos "italianos".

Uma vez gravadas, as entrevistas são transcritas ${ }^{8}$, para que se proceda com a análise, e as respostas são organizadas pergunta por pergunta, para que possam ser observadas recorrências e elementos de interesse.

Nossa convicção é que, dessa forma, podemos olhar para a imigração italiana no Brasil por meio das histórias de seus protagonistas, pois, concordando com Borelli (1992), consideramos que

[...] evidenciar o passado no presente imediato das pessoas, através dos depoimentos orais, constitui essa possibilidade de reconstrução e compreensão da história humana. Neste sentido, a memória, a experiência e o tempo são fundamentais para essa recuperação do vivido conforme concebido por quem viveu. Memória no sentido de fonte do passado no presente, como busca daquele tempo no agora, transcendendo a mera cronologia [...]. (p. 81, grifo nosso)

Para este trabalho, foram selecionadas e analisadas cinco das entrevistas mais recentes e a duração de cada uma delas varia entre 20 e 50 minutos. Os entrevistados são três docentes universitários, uma professora de italiano e um empreendedor, cujas famílias chegaram ao Brasil entre o final do século XIX e os primeiros anos do século XX. A amostra é aleatória e a análise, que, como dissemos, é de tipo qualitativo e exploratório, busca observar como o "eu" se constitui e como se manifestam as categorias de pessoa, tempo e espaço. Foram selecionados exemplos que podem nos ajudar a refletir sobre alguns fenômenos específicos e, em particular, a pensar sobre as modalidades da narração e o modo como se constrói.

\section{NARRAR A "ITALIANIDADE"}

Como mencionado, entendemos aqui por "italianidade" o conjunto de elementos que se constituem no próprio discurso, criando a ideia de pertencimento a uma origem comum, que se afirma na relação entre o "eu" e o "outro".

Ouvindo as entrevistas selecionadas e lendo as transcrições, emergem imediatamente recorrências temáticas que criam isotopias, ou seja, como dizia Greimas (1966), a repetição, na cadeia enunciativa, de mais elementos que representam uma unidade de sentido, permitindo assim concluir que questões como, por um lado, a procura das próprias origens e, por outro, a Itália e a "italianidade", vistas em sua relação com o Brasil (a música, a ópera, a literatura, a comida, mas também o trabalho, a luta pela sobrevivência etc.), ocupam um lugar central.

\footnotetext{
${ }^{8}$ Para a transcrição, utilizamos uma versão adaptada do método jeffersoniano (Sacks et al., 1974).
} 
Sobre o tema da "busca da identidade", foram selecionados alguns trechos extraídos das cinco entrevistas ${ }^{9}$. Observemos dois breves excertos da primeira entrevista:

(D1)

00'34' Eh eu sou descendente de italiano dos dois lados então que vamo- assim por partes a família $\operatorname{Axxx}^{10}$ que era do::: por parte do meu pai e a família Dxxx que era por parte da minha mãe

01'05', [...] tive mais contato [com] os Axxx entã::o eu me especializei mais nas minhas pesquisas pela família Axxx tanto que eu peguei a cidadania italiana po- por essa linhagem do meu bisavô avô pai e chegou até a mim ${ }^{11}$

Como aponta a indicação do tempo ao lado das palavras transcritas, a entrevista acabou de começar (quando é falado o primeiro trecho, transcorreram somente 34 segundos do início da gravação) e o entrevistado, para responder à pergunta (1) que, relembrando, focaliza o que o entrevistado sabe de como a sua família veio para o Brasil, se define imediatamente como descendente, menciona as pesquisas realizadas na família para descobrir mais sobre suas origens e conclui dizendo que "pegou" a cidadania italiana, isto é, em certo sentido, se "reapropriou" de sua ligação com a Itália.

Chama a atenção que o entrevistado use logo a primeira pessoa (não fala dos outros membros da família, mas apenas de si mesmo) e se coloque como principal agente da história que narra: é o "eu" que descende de italianos, seja pelo lado materno que pelo paterno e que, ainda, teve um papel ativo, dado que fez pesquisas sobre a família, principalmente do lado materno, que o levaram a criar as condições para obter a nacionalidade italiana.

Assim como acontece aqui, também nas outras entrevistas, desde o início, é constante a presença de elementos que remetem à primeira pessoa (pronomes, verbos em primeira pessoa, possessivos de primeira pessoa singular etc.), como se houvesse, por parte dos entrevistados, a imediata necessidade de dizer "eu" para se definir como protagonistas dos fatos narrados. Vejamos outros exemplos:

(J2)

00' 30" Posso dizer duas coisas primeiro que eu sou a única pessoa da família dos descendentes que se interessa por isso \#

01' 14" é essa parte italiana da família foi a que pra mim ficou mais é digamos assim impregnada né foi aquela com a qual eu mais me identifico então

\footnotetext{
${ }^{9}$ Para identificar os cinco entrevistados, escolhemos as seguintes siglas: D1, J2, N3, D4 e M5, nas quais a letra é a inicial do nome e o número está na sequência.

${ }^{10}$ Os nomes próprios serão sempre abreviados e representados pela letra inicial seguida por três ' $x$ ', de modo que possam ser identificados.

${ }^{11} \mathrm{O}$ negrito utilizado nos trechos extraídos das entrevistas é sempre nosso.
} 
(N3)

00'36" \# Olha a:: eu sou- tenho ascendência italiana pelos dois lados materno e paterno \# hã:: do lado materno são:: \# meus dois avós eram italianos

(D4)

00' 06" Eh:: na verdade eu fiz uma pesquisa muito grande depois de eu ter uns quinze anos de idade com quinze anos no primeiro colegial alguma coisa assim eu peguei o meu livro de história e falei não tinha guerra nessa época não é possível \# não tinha primeira guerra mundial não tinha começado não sei o quê aí eu comecei a pesquisar e a tentar entender o que tinha acontecido

07'18' Eu trabalhei bastante essas cartas porque foi uma espécie de redescoberta de::: da minha origem

Percebe-se uma marcante recorrência tanto na construção do início das entrevistas, quanto nos temas abordados. Os entrevistados, antes de contar o que sabem sobre como seus antepassados chegaram ao Brasil e sobre o que fizeram, se identificam como descendentes e, mais ainda, como "membros especiais" de suas famílias por terem sido aqueles que buscaram redescobrir suas origens e encontrar informações sobre as histórias de seus antepassados. As pesquisas realizadas, o trabalho de recuperar documentos e memórias, os esforços pessoais para entender os acontecimentos do passado se apresentam no discurso como "provas" de uma identificação com essa ligação, que vai além do simples fato de haver italianos em sua ascendência.

$\mathrm{Na}$ entrevista de (M5), o "eu" como agente e como protagonista da sua história e da sua ligação com a Itália e com a italianidade, aparece em um momento um pouco posterior da entrevista, comparando com as outras quatro. No excerto a seguir, estamos quase no décimo nono minuto da entrevista, quando se afirma o papel de quem "se empenha" para conhecer as histórias de famílias que parecem não interessar a mais ninguém. Vejamos:

(M5)

18'59" aí- aí quando eu vi as coisas \# ele se chamava Sxxx não era \# Sxxx Pxxx Gxxx aí eu falei- aí que:: aí eu \#\# eu era a única pessoa na família até hoje que sabe que o nome do nono era Sxxx Pxxx Gxxx

O elemento que evidenciamos neste excerto é, mais uma vez, aquele do protagonista da história que "quis saber" e que "sabendo" assume o papel da "autoridade", de quem conhece a história da própria família graças ao próprio esforço.

Observamos, portanto, em todas as entrevistas, a necessidade de afirmarse como indivíduo, como eu que agiu e age. Ver, um abaixo do outro, os trechos transcritos deixam esse procedimento ainda mais claro:

(D1) 00'34, [...] eu sou descendente de italiano dos dois lados

(J2) 00'30", [...] eu sou a única pessoa da família dos descendentes que se interessa por isso 
(N3) 00'36',

[...] eu sou- tenho ascendência italiana pelos dois lados materno e paterno

(D4) 00'06',

Eh:: na verdade eu fiz uma pesquisa muito grande

(M5) 18'59',

[...] eu era a única pessoa na família até hoje que sabe que o nome do nono era Sxxx Pxxx Gxxx

Como dizia Benveniste (1995), "sou eu se digo eu” e é isso que esses descendentes parecem querer reafirmar:

$E u$ só pode definir-se em termos de "locução", não em termos de objetos, como um signo nominal. $E u$ significa "a pessoa que enuncia a presente instância de discurso que contém $e u$ ”. Instância única por definição, e válida somente na sua unicidade. (p. 278)

Embora o "outro" seja logo incluído no discurso (são citados a família, os antepassados vindos da Itália, o lado materno e o lado paterno), é o "eu” que importa e se coloca como protagonista, fazendo, dessa maneira, um movimento em direção a uma reafirmação da identidade - "eu sou” - e da italianidade - "eu sou descendente", encontradas com o empenho pessoal, após terem sido, de alguma forma, perdidas e silenciadas pelo tempo e pelo modo como se configuraram as histórias.

\section{TEMPO, PESSOA E MEMÓRIA: O ‘EU’ DESDOBRADO}

Nesta seção, serão discutidos os excertos nos quais foi analisada a questão do "eu" narrante, que conta agora - no presente - e insere, entre outras coisas, as modalizações do discurso ( $e u$ acho que) e os sinais constitutivos da narração em curso (eu sei que, eu imagino, eu me lembro); e do "eu" narrado, a pessoa de quem se narra - no passado -, que entra na história narrada como protagonista e como personagem. As categorias foram utilizadas já por Spitzer (1928) e também por Genette (1972), para o qual o "eu” narrante (erzählendes ich) é o actante que instaura o "eu" narrado (erzähltes $i c h$ ) na história por meio de analepses, isto é, de movimentos retrospectivos que olham para o passado a partir do presente da narração. Observemos o exemplo a seguir:

(D4)

23'53" eu acho que até hoje a gente tem uma visão daquela época dos italianos que::: \# de uma Itália muito \# romântica de uma Itália que não existe mais me lembro de -tá numa festa de::: Natal em Napoli e de final de ano de uma empresa e tinha um grupo de músicos napolitanos cantando algumas músicas que pra:: pra nós são super famosas e aí eu comecei a cantar as pessoas me olhavam e falavam mas como você sabe essas músicas nós não sabemos é música de mil- do final do ottocento e eu falei ah tudo bem mas no Brasil ainda é assim são essas músicas de fes- dessas festas italianas eu acho que hã::: \# essa visão continua até hoje né bem marcada bem estereotipada mas talvez eles eu imagino também que eles tenham sido vistos como lutadores é a imagem que é o que eu imagino não sei se é verdade como pessoas trabalhadoras que::: vieram pra::: ganhar \# ganhar a vida construir a vida aqui no Brasil. 
Narrando a própria história e o modo como se constitui, o "eu" está tanto dentro quanto fora da narração de si mesmo (Volóshinov, 2017), presente e passado se mesclam e o espaço da memória é filtrado pelo presente. Como se vê nas ocorrências evidenciadas, na superfície, no nível da enunciação, aparece o "eu" narrante (eu acho que; me lembro; eu imagino), que se desdobra e dá a vez para o "eu", sujeito do enunciado, protagonista da história narrada (eu comecei a cantar; as pessoas me olhavam). Desse modo, a evocação da memória faz o "eu" sentir a emoção vivenciada no passado, seja quando narra de si mesmo no passado, seja no caso em que narra do outro.

Nesse sentido, seguem abaixo mais dois exemplos:

(D1)

29'43" 'Eu tenho uma lembrança também nós estávamos falando de lembrança do::s dos italianos [...] pra deixar registrado perguntei pra minha tia há algum tempo atrás qual foi a primeira lembrança que a senhora tem de criança? [...] eu tenho umas lembranças todo mundo tem uma lembrança um primeiro fragmento de memória e ela falou $<$ a:: me lembro de um dia uma tarde de sol tipo meio dia uma hora hã:: no sítio \# e que todos os colarinhos das camisas tavam sendo quaradas

(N3)

12'51' E ela então contava as histórias cantava muitas músicas músicas infantis tinha uma que ela cantava que eu me lembro \# da chuva piove piove il cielo l'acqua di San Pietro la gatta si bagnava perché ti bagni gatta \# então eu fui embalada com todas essas essas coisas né \# e aí ela- e aí a gente fazia perguntas pra ela e então ela contava de quando ela era criança de como era de como eram os muros de como era a muralha de como era Lucca.

No excerto de (D1), o "eu” narrante introduz um outro que também fala em primeira pessoa, enquanto no de (N3), há, como no primeiro exemplo, uma sobreposição entre a pessoa que narra e a pessoa de quem se narra. Em todos os casos, no entanto, o "eu" narrante introduz o "eu" narrado e o tempo da memória e, assim, utilizando a primeira pessoa, o "eu" ocupa no texto o papel da testemunha que convence por ter vivido, narrando "si mesmo" e tornando-se, portanto, também ator.

O desdobramento do "eu" fica claro no quadro abaixo (Quadro 1), que, retomando as principais ocorrências dos três exemplos selecionados, corrobora quanto dito acima:

QUADRO 1 - "EU” NARRANTE E "EU” NARRADO: EXEMPLOS EXTRAíDOS DAS ENTREVISTAS

\begin{tabular}{|l|l|l|}
\hline & eu narrante & eu narrado \\
\hline (D4) & $\begin{array}{l}\text { eu acho que } \\
\text { eu acho que } \\
\text { eu me lembro } \\
\text { eu imagino } \\
\text { eu imagino }\end{array}$ & $\begin{array}{l}\text { eu comecei a cantar } \\
\text { me olhavam } \\
\text { eu falei }\end{array}$ \\
\hline (D1) & eu tenho uma lembrança & $\begin{array}{l}\text { me lembro de um dia uma tarde de sol } \\
\text { eu me lembro } \text { embalada }\end{array}$ \\
\hline (N3) & $\begin{array}{l}\text { a gente [eu e os outros] fazia perguntas } \\
\text { pra ela }\end{array}$ \\
\hline
\end{tabular}


Os exemplos mostram ainda que, para unir o presente da enunciação e o passado da memória, aparece o "eu" que lembra ("me lembro"; "tenho uma lembrança") e dá espaço para o tempo da memória que faz reviver o que está sendo contado, pois "um evento vivido acabou, ou pelo menos está fechado na esfera da experiência vivida, enquanto um evento lembrado não possui limites, porque é somente a chave para tudo aquilo que ocorreu antes e depois dele" (Benjamin, 1973, p. 28).

Torna-se, portanto, significativo observar a repetição do verbo "lembrar" e do substantivo "lembrança" que abundam nos trechos selecionados, mostrando e marcando como a memória vem à superfície do texto. Estabelecem-se, assim, novas relações também no tempo que não é apenas tempo físico, isto é, tempo uniforme, infinito, linear, segmentável, ou tempo crônico, em uma sequência de acontecimentos, como dizia Benveniste (1995), mas é um tempo que se reorganiza na memória e se manifesta na língua, ligado ao discurso, ordenando-se e definindo-se em relação ao próprio discurso.

No tempo da língua, o centro gerador e axial, a partir do qual tudo se redefine, é o presente da instância do discurso e usar o presente significa situar o acontecimento como contemporâneo ao momento do discurso, que não poderá ser localizado em uma divisão particular do tempo crônico, porque é reinventado todas as vezes que é lido, transformando-se, assim, em um momento novo, literalmente, ainda não vivido.

O tempo - como está claro - não relata o tempo "objetivo", visto que a língua não é uma reprodução da realidade, mas uma (re)construção do real, diversa da realidade. É desse modo que na narração, presente e passado se alternam, constituindo planos temporais que se movem, "filtrados" pela memória e pela experiência.

\section{TEMPO E ESPAÇO: ENTRE A ITÁLIA E O BRASIL}

Reflexões tão instigantes quanto as anteriores podem ser feitas a partir da observação do espaço da memória e da maneira como se apresenta nesses textos. Trata-se, em quase todos os casos, de uma memória que se encontra na "fronteira" entre Itália e Brasil, representada pelas ideias de nacionalidade e língua ou por um deslocamento real, e que permite referências oscilantes para quem fala.

Vejamos os exemplos:

(M5)

09'03" então nós éramos::: eu e:: era os meninos e conversávamos o que você vai ser? Eu vou ser italiano eu vou assumir a nacionalidade italiana 
14'10" eu escrevo:: penso palavras que pra mim são em português e não \# elas são italianas.

(D4)

11'50', Exatamente e::: \# e foi isso então hã::: ficou sempre essa grande lacuna na na minha família né \# do onde tá a família na Itália? Por que estamos aqui? Por que somos os únicos a estar aqui?

(N3)

14'09" ir pra Itália era uma coisa assim era um sonho muito grande e o:: mas o sonho \# claro que eu queria ir a Roma ir a outros lugares a Veneza tudo estive em tudo isso mas meu grande sonho era ir a Lucca \# o meu grande sonho era ir a Lucca e:: a tal ponto de quando eu cheguei em Lucca [...] quando eu desci do trem e pisei em Lucca eu caí em prantos porque era assim- era uma coisa hã:: mágica pra mim estar ali e:: vendo aquela cidade eu sentia que meus olhos não eram só meus eram os olhos da minha mãe dos meusdos meus tios né dos meus primos do meu irmão que que porque né porque Lucca era a grande cidade a grande protagonista das histórias nossas né \#

No quadro a seguir (Quadro 2), podem ser visualizadas as marcas de espaço, relacionadas às de tempo, que se alternam na fala dos sujeitos:

QUADRO 2 - REPRESENTAÇÕES DO ESPAÇO: EXEMPLOS EXTRAÍDOS DAS ENTREVISTAS

\begin{tabular}{|c|c|c|}
\hline (M5) & 09'03" & $\begin{array}{l}\text { [...]nós éramos:.: eu e:: era } \\
\text { o que você vai ser? Eu vou ser italiano eu vou assumir a nacionalidade italiana }\end{array}$ \\
\hline (M5) & $14^{\prime} 10^{\prime \prime}$ & $\begin{array}{l}\text { [...] ]eu escrevo:: penso palavras que pra mim são em português e não \# } \\
\text { elas são italianas. }\end{array}$ \\
\hline (D4) & 11'50', & $\begin{array}{l}\text { [...] Jonde tá a família na Itália? Por que estamos aqui? Por que somos } \\
\text { os únicos a estar aqui? }\end{array}$ \\
\hline (N3) & 14'09'” & 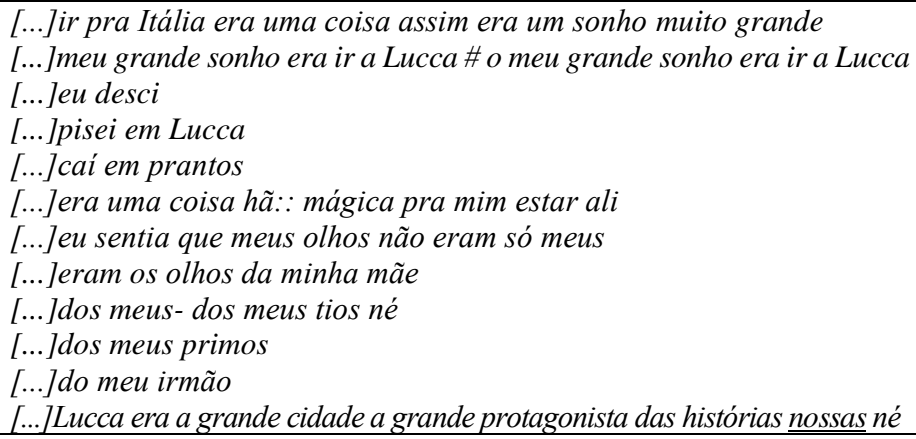 \\
\hline
\end{tabular}

O "desdobramento", o estar "aqui" e "lá", preenchido de diferentes maneiras ao longo das entrevistas, aparece nas oscilações dos pronomes, tais como a primeira pessoa do plural, um "nós" inclusivo no qual o sujeito se coloca como parte de um grupo, logo substituído pela primeira pessoa do singular "eu", afirmando, em seguida, a "identidade" italiana, citada explicitamente. Segue uma referência às línguas: o entrevistado diz que o português brasileiro - a "língua daqui" - e o italiano - a "língua de lá" - se confundem, como se isso, de alguma forma, representasse modos distintos de ver e viver. 
O “aqui" e o "lá" são tematizados também na fala de (D4) para a qual a Itália é lá e o Brasil é o aqui. Por outro lado, as perguntas (Por que estamos aqui? Por que somos os únicos a estar aqui?) mostram que o "aqui" e o "lá" representam uma cisão, que é consequência da migração e age com especial força naqueles aos quais pouco foi dito sobre o início da migração, que não sabem as razões que causaram a separação.

Uma tematização do "aqui” que é o Brasil e do "lá" que é a Itália ocorre também em (N3), que traz a Itália para o discurso como o lugar de conexão com as origens e da retomada da consciência sobre uma identidade. Marcando a posição do narrador da história como protagonista, os possessivos da primeira pessoa do singular ( $\mathrm{meu} / \mathrm{s}$; minha) se repetem na entrevista e evidenciam que o centro continua sendo o "eu”, que, ao mesmo tempo, reúne toda a família e menciona também as "histórias nossas", unindo-se, também na fala, ao grupo do qual faz parte.

\section{CONSIDERAÇÕES FINAIS}

A análise conduzida nos permite voltar às perguntas que nos colocamos no início e que foram formuladas para nos guiar ao longo deste artigo. Nossa proposta foi investigar a relação com a Itália e a "italianidade" de descendentes, já nascidos no Brasil, com o objetivo de observar o modo como aparece nas narrativas essa parte de sua história e focalizando, em especial, a constituição do "eu" no discurso, entrelaçada com as categorias de tempo e espaço.

Um primeiro aspecto que merece destaque é a postura dos entrevistados frente à sua "história". Embora tenhamos analisado aqui apenas cinco das entrevistas, é notável a regularidade que se observa no movimento de assumir a posição de protagonistas logo nos primeiros momentos da gravação, apontando para a imediata necessidade de se colocar como um "eu", que define o lugar central de quem fala de si. Atitudes semelhantes já foram observadas também em outras entrevistas do corpus e confirmam uma tendência à autoafirmação, dada também pela posição de "testemunha", que a própria situação da entrevista constrói.

O "eu” se coloca e é, desde o início, o agente ativo de sua italianidade, capaz de recuperar, por meio de ações (como a busca de documentos e informações, por exemplo) e de memórias de fatos e lugares, uma identidade, entendida como pertencimento, que, em suas palavras, seus antepassados não cuidaram de transmitir. A língua não foi ensinada, as histórias sobre a vida de antes da chegada ao Brasil raramente foram contadas, os documentos da família não foram guardados com o necessário cuidado e é, portanto, papel daqueles que querem se reapropriar dessa parte de sua história buscá-la e reorganizá-la. Ao mesmo tempo, chama 
a atenção nas cinco entrevistas a recorrência de temas e traços, que aparecem como representações da Itália e se concretizam, por exemplo, na referência às comidas e à música, mas também às características dos italianos ligadas ao trabalho, por exemplo, cuja presença define os contornos do pertencimento, inserido no discurso.

Tudo isso é sempre narrado a partir da explicitação da lembrança, do filtro da memória: "eu lembro", "eu tenho uma lembrança" repetem insistentemente os entrevistados e marcam uma subjetividade, mais uma vez, colocada no centro como eixo definidor. Essa memória vincula-se à percepção e à narração e o "eu" se divide em "eu narrante" e "eu narrado", introduzindo o tempo da memória e acessando o passado do próprio sujeito e de sua família para trazê-lo ao presente da enunciação, no qual, porém, o “eu” não é mais o mesmo, pois, como escreveu Bakhtin:

Se eu narrar (ou escrever) uma ocorrência que acaba de se passar comigo, como narrador (ou escritor), já estarei fora daquele tempo-espaço onde se deu tal acontecimento. A identificação absoluta de mim mesmo, do meu "eu" com aquele "eu" sobre quem narro, é tão impossível como erguer a si mesmo pelos cabelos. (2018, p. 234)

O desdobramento do "eu" se dá, assim, no tempo do agora e do então e no espaço do aqui e do alhures. No tempo, o "eu" que narra traz para o agora lembranças do passado, revisitadas e revividas, alternando os planos temporais incluídos nas narrativas, redeterminando a sequência dos acontecimentos e reorganizando-se no próprio discurso. Evidencia-se, desse modo, uma predominância do papel desempenhado pelo presente, que, concomitante com o momento da enunciação, filtra as memórias, se afasta do tempo objetivo e permite reviver o que está sendo narrado. No espaço, por outro lado, o "eu” se coloca entre o aqui do Brasil e o alhures da Itália, que, no entanto, mais do que uma rígida separação é a criação de um limiar, de um espaço híbrido, que reconhece no aqui também elementos constitutivos do alhures, trazidos da Itália para o Brasil pelos antepassados de quem está falando e mantidos por eles próprios, que são, de alguma forma, elos desse tempo-espaço.

A "grande imigração" italiana no Brasil teve, desde seu início, números extraordinários que se multiplicaram em vidas de "pessoas comuns", que, ao narrar, dizem "eu" e se colocam como protagonistas de suas histórias. Continuaremos nosso trabalho de dar voz a elas para que nos revelem, partindo dos caminhos de suas memórias, como conjugam passado e presente e como se movem entre os espaços de origem e de destino para constituir seu "eu" e sua identidade. 


\section{REFERÊNCIAS}

Amossy, R. (2011). La notion de stéréotype dans les sciences sociales. In R. Amossy \& A. Herschberg-Pierrot (eds.), Stéréotypes et clichés. Langue, discours, société (3a ed., pp. 33-53). Armand Colin.

Bakhtin, M. (2018 [1895-1975]). Teoria do romance II. As formas do tempo e do cronotopo. Tradução, posfácio e notas P. Bezerra. São Paulo: Editora 34.

Balthazar, L. L. (2016). Atitudes linguísticas de italo-brasileiros em Criciúma (SC) e região [Tese de doutorado, Universidade Federal do Paraná]. AcervoDigital da UFPR. https://acervodigital.ufpr.br/handle/1884/42879?show=full

Benjamin, W. (1973). Avanguardia e rivoluzione. Saggi sulla letteratura (A. Marietti, trad.). Einaudi.

Benveniste, É. (1995). Problemas de linguística geral I (4a ed.). Pontes.

Borelli, S. H. S. (1992). Memória e Temporalidade: Diálogo entre Walter Benjamin e Henri Bergson. EDUC.

Bruni, F. (2013). L'italiano fuori d'Italia. Franco Cesati.

Castellani, A. (2009). Quanti erano gl'italofoni nel 1861? In V. Della Valle, G. Frosini, P. Manni \& L. Serianni (eds.), Nuovi saggi di linguistica e filologia italiana e romanza (1976-2004) (pp. 117-138). Salerno.

Cenni, F. (2011). Italianos no Brasil (3a ed.). Editora da Universidade de São Paulo.

De Mauro, T. (1963). Storia linguistica dell'Italia repubblicana dal 1946 ai nostri giorni. Laterza.

de Oliveira, G. M. (2008). Plurilinguismo no Brasil. Organização das Nações Unidas para a Educação, a Ciência e a Cultura (UNESCO); Instituto de Investigação e Desenvolvimento em Política Linguística (IPOL).

Ferreira, M. M. (1998). Os desafios da história oral nos anos 90. Revista de História Oral, (1), 19-30. https://doi.org/10.51880/ho.v1i0.90

Fiorin, J. L. (1995). A pessoa desdobrada. Alfa, (39), 23-44.

Franzina, E. (1995). L'emigrazione italiana in America (1492-1942). Mondadori.

Franzina, E. (2006 [1976]). A Grande Emigração: O Êxodo dos Italianos do Vêneto para o Brasil (E. Toledo e L. Biondi, trad.). UNICAMP.

Frosi, M. V. \& Mioranza, C. (1975). Imigração Italiana no Nordeste do Rio Grande do Sul. Movimento.

Genette, G. (1972). Figures III. Seuil.

Greimas, A.-J. (1966). Sémantique structurale. Larousse.

Halbwachs, M. (1999). A memória coletiva. Vértice.

Hall, S. (2003). A identidade cultural na pós-modernidade. DP\&A.

Honório, A. R. R. (2016). Descendentes de (i)talianos de Cascavel/PR: língua e cultura encobertas [Tese de doutorado, Universidade de São Paulo]. Biblioteca Digital USP. https://teses.usp.br/teses/disponiveis/8/8148/tde-09032017-104313/pt-br.php

Hutter, L. M. (1986). Imigração italiana em São Paulo de 1902 a 1914. Processo imigratório. Instituto de Estudos Brasileiros; Universidade de São Paulo. 
Klein, H. S. (1989). A integração dos imigrantes italianos no Brasil, na Argentina e Estados Unidos. Novos estudos, (25), 95-117.

Manfroi, O. (1975). A colonização italiana no Rio Grande do Sul: Implicações econômicas, politicas e culturais. Instituto Estadual do Livro.

Matos, J. S., \& DeSenna, A. K. (2011). História oral como fonte. Historice, 2(1), 95-108.

Meihy, J. C. S. B. (2012). História oral e identidade. Caipira, espelho, espelho meu? Revista do Patrimônio histórico e artístico nacional, (34), 411-425.

Meihy, J. C. S. B., \& Holanda, F. (2007). História oral: como fazer, como pensar. Contexto.

Payer, M. O. (2006). Memória da língua. Imigração e nacionalidade. Escuta.

Sacks, H., Schegloff, E. A., \& Jefferson, G. (1974). A simplest systematics for the organization of Turn-taking for conversation. Language, 50(4), 696-735. https://doi.org/10.1353/lan.1974.0010

Scherer, A. E. (2007). A constituição do eu e do outro pela interpelação da língua pela língua na história do sujeito. In M. C. Ferreira \& F. Indursky (eds.), Análise do discurso no Brasil: mapeando conceitos, confrontando limites (pp. 347-356). Claraluz.

Spitzer, L. (1928). Stilstudien. München.

SVIMEZ (Associazione per lo Sviluppo dell'Industria nel Mezzogiorno). (1954). Statistiche sul Mezzogiorno d'Italia, 1861-1951.

Trento, A. (1989). Do outro lado do Atlântico. Um século de Imigração Italiana no Brasil (M. Fabris \& L. E. de Lima Brandão, trad.). Nobel.

Truzzi, O. (2016). Italianidade no interior paulista. Percursos e descaminhos de uma identidade étnica (1880-1950). Unesp.

Vezzelli, E. (2015). A construção do ethos discursivo na imprensa em língua italiana em São Paulo: o caso de La Difesa [Tese de doutorado, Universidade de São Paulo]. Biblioteca Digital USP. http://www.teses.usp.br/teses/disponiveis/8/8148/tde-11032016-153524/pt-br.php

Volóshinov, V. (2017). Marxismo e filosofia da linguagem. Problemas fundamentais do método sociológico na ciência da linguagem (S. Grillo \& E. Vólkova, trad.). Editora 34.

Weber, R. (2013). Estudos sobre imigrantes e fontes orais: identidade e diversidade. Revista de História Oral, 16(1), 5-21. 